\title{
A PROBABLE 17-18 TRISOMY SYNDROME WITH PHOCOMELIA, EXOMPHALOS, AND AGENESIS OF HEMIDIAPHRAGM
}

\author{
BY
}

\author{
TADASHI KAJII, KIYOSHI OIKAWA, KATSUAKI ITAKURA, and TADASHI OHSAWA \\ From the Department of Paediatrics, and The Department of Pathology, Hokkaido University School of Medicine, \\ and the Department of Radiology, Sapporo Medical School, Japan
}

(RECEIVED FOR PUBLICATION MARCH 5, 1964)

During a survey of thalidomide embryopathy (Kajii and Shinohara, 1963), an infant with a peculiar combination of malformations was found among the 150 cases of the syndrome. This infant exhibited phocomelia of the left arm which resembled closely that of thalidomide embryopathy, but in addition showed most of the features characteristic of the 17-18 trisomy syndrome. In the 17-18 trisomy syndrome is seen a variety of deformities of the extremities: flexion of fingers with the index finger overriding the third and the fifth finger overriding the fourth; retroflexible thumb; short or long fifth finger; ulnar or radial deviation of the wrist; abnormal dermal patterns; hypoplastic finger- and toe-nails; rocker-bottom feet; hammer big toes; syndactyly of toes; posterior prominence of heels; and limited hip adduction (Edwards, Harnden, Cameron, Crosse, and Wolff, 1960; Smith, Patau, Therman, and Inhorn, 1960, 1962; German, Rankin, Harrison, Donovan, Hogan, and Bearn, 1962; Uchida, Bowman, and Wang, 1962; Gottlieb, Hirschhorn, Cooper, Lusskin, Moloshok, and Hodes, 1962; Hecht, Bryant, Motulsky, and Giblett, 1963). However, phocomelia of the arm has not been described in combination with this syndrome. In addition to phocomelia, the infant showed a giant exomphalos and agenesis of the left hemidiaphragm, hitherto undescribed in the 17-18 trisomy syndrome.

\section{Case Report}

The infant, a male, was delivered at 34 weeks of gestation by caesarean section at Hokushin Hospital on September 15, 1958. His mother was para $O$, gravida 1 , aged 24 at delivery, and had had ante-partum haemorrhage and hydramnios. The infant weighed $1,700 \mathrm{~g}$. at birth, length $36.5 \mathrm{~cm}$., and died immediately after birth. As yet we have been unable to locate the parents.

We found the infant in August 1963, after the body had been preserved in formalin solution for nearly five years (Figs. 1-4).
Radiology. The left arm demonstrated a 'flask'-shaped bone for the hypoplastic humerus. Ulna was hypoplastic and radius was absent. Two metacarpals and corresponding two phalanges were seen within the fin-like hand which was held in flexion and in radial deviation. On the right, there was a normal humerus, and slightly shortened radius and ulna. The second to fifth metacarpals. proximal, middle, and poorly ossified distal rows of phalanges appeared normal. In the lower extremities. the femur, tibia, and fibula were normal; the distal femoral and proximal tibial ossification centres were absent. In the tarsus the only ossification centre present was in the calcaneus. There were five normal-appearing metatarsals and a somewhat poorly ossified proximal row of phalanges. The distal row of phalanges was not ossified. It was concluded that the bone age was premature for the infant's chronological age. The clavicle was deformed on the left. The ribs were slender and irregularly spaced (Fig. 4). Only two ossification centres were noted in the sternum. The pelvis appeared small relative to the trunk and lower extremities; the acetabular and iliac angles were normal.

Necropsy. The infant showed a marked lack of subcutaneous tissue and an excessive lanugo over the trunk and extremities. The head measured $31.5 \mathrm{~cm}$. with $10 \cdot 8 \mathrm{~cm}$. fronto-occipital and $8 \cdot 1 \mathrm{~cm}$. biparietal diameters. The occiput was prominent. The anterior fontanelle measured 2.5 by $2.5 \mathrm{~cm}$. and the posterior fontanelle was 4.0 by $4.0 \mathrm{~cm}$. in diameter. The ears were low set and malformed: helix was underdeveloped and more ovoid; antihelix was absent; lobule was small; tragus was lacking; and the meatus allowed a probe only $5 \mathrm{~mm}$. on the right and $9 \mathrm{~mm}$. on the left. The palpebral fissures measured $13 \mathrm{~mm}$. on the right and $15 \mathrm{~mm}$. on the left. There were hypertelorism and bilateral epicanthic folds. The mouth was kept open, and was small and triangular in shape. There was a high-arched palate. The neck was short with loose skin folds on the lateral aspects.

The right arm was deformed with slightly shortened radius and ulna, a 160-degree flexion of the wrist, and the fingers partially flexed with the index finger overriding the 


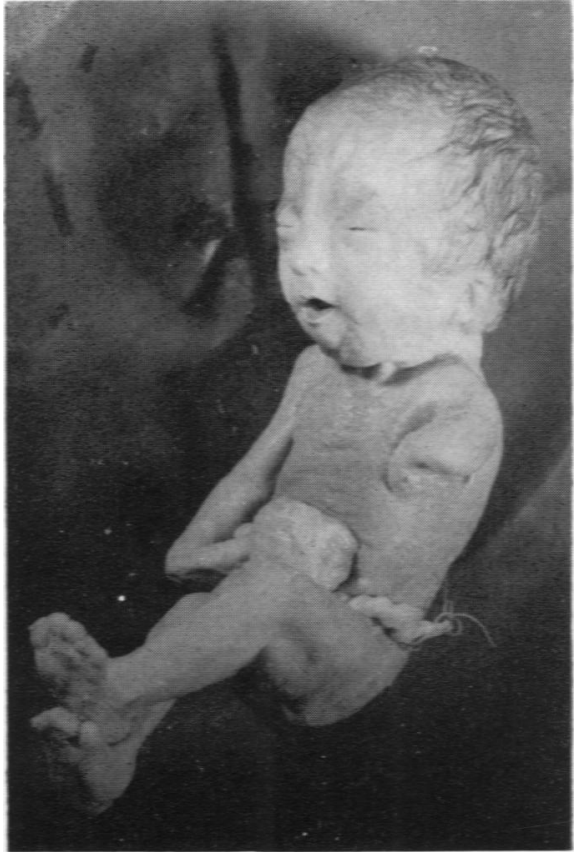

Frg. 1.-Appearance of the infant showing low-set malformed ears, small triangular mouth, receding chin, phocomelia of left arm. exomphalos, and rocker-bottom feet. Photograph was taken 5 years post mortem.

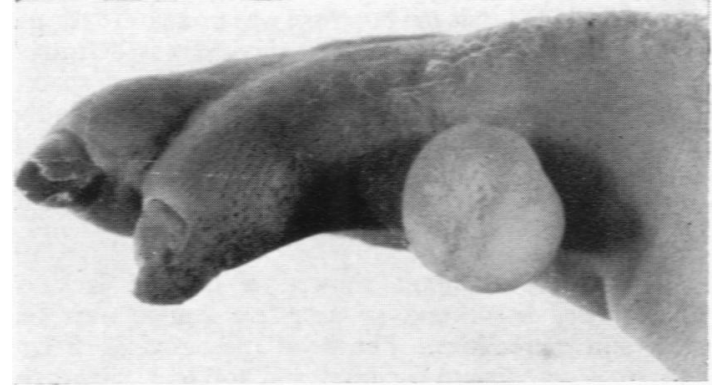

FG. 2.-Right hand, showing bud-like hypoplastic thumb, flexion of fingers with the index finger overriding the third. hypoplastic fingernails, and a transverse palmar fiexion crease.

third. The thumb was a bud-like soft tissue mass and attached to the base of the index finger with a narrow pedicle. The fingernails were hypoplastic. There was a deep transverse palmar crease. There was phocomelia affecting the left arm: there were only three fingers; the thumb was missing; the index and third fingers were almost totally webbed and appeared fin-like. These two fingers each had two fingernails on opposite sides. There was a bud-like fourth finger attached to the matacarpophalangeal joint of the third finger. The wrist was partially flexed with a 100-degree radial deviation.

The hips and knees were partially flexed and the feet

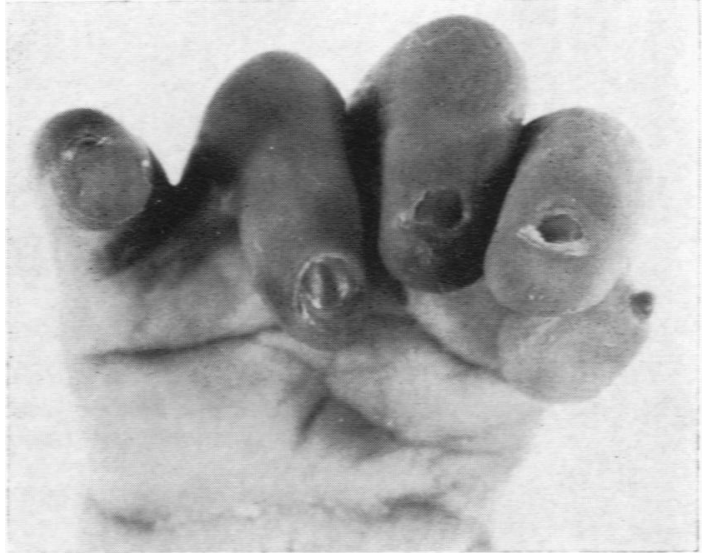

Fig. 3.-The left hand seen from the ulna side. Soft tissue syndactyly between the index and third fingers. and hypoplastic hyperconvex fingernails. Note the index finger has two fingernails on opposite sides. A bud-like finger is attached to the metacarpophalangeal joint of the third finger.

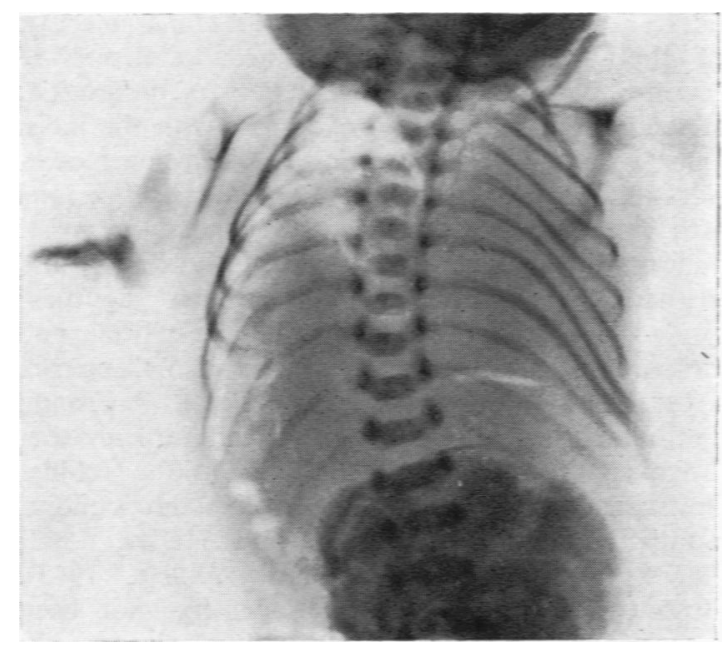

Fig. 4.-The left thoracic cavity is filled by the intestine. The ribs are slender and irregularly spaced. Note: This photograph is reversed.

were crossed over. There were symmetrical deformities of the feet with convex soles and posterior extension of the heels. The big toes were shorter than the second and the right big toe was held in a dorsiflexed position. There was a partial webbing between the third and fourth toes on the right and of the second and third toes on the left. The toe-nails were hypoplastic.

The thoracic cage was wide in the anterior and posterior diameter with the right hemithorax prominent over the left. The nipples were widely spaced. The sternum was $1.2 \mathrm{~cm}$. in length and was shortened. The fingerprints could not be discerned after the long preservation period. 
TABLE

SUMMARY OF ABNORMAL FINDINGS

\author{
A : General \\ Age of the mother, 24 years \\ Age of the mother, 24 \\ B: Central nervous system \\ B: Central nervous system \\ Agenesis of falx cerebri \\ C: Branchial \\ Low-set malformed ears* \\ D: Arches and face \\ Small palpebral fissures* \\ Hypertelorism \\ Inner epicanthic folds \\ Small triangular mouth \\ High-arched palate \\ Receding chin \\ E: Cardiorascular \\ Dextroposition of heart \\ High posterior membranous interventricular septal defect * \\ Bicuspid pulmonic valve \\ Single umbilical artery* \\ F: Pulmonary \\ Abnormal lobulation of lungs* \\ $G$ : Gastro-intestinal \\ Mesenterium commune* \\ Dilatation of sigmoid and rectum* \\ Riedel's lobe of liver \\ H: Musculo-skeletal \\ Prominent occiput \\ Large fontanelle \\ Short sternum \\ Irregularly spaced slender ribs \\ Small pelvis \\ Short right radius and ulna* \\ Ulnar deviation of right index finger \\ Flexion of right wrist \\ Phocomelia of left arm* \\ Aplasia and hypoplasia of thumbs* \\ Olygodact yly* \\ Crossed feet \\ Rocker-bottom feet \\ Posterior prominence of heels \\ Hypoplast ic big toes \\ Dorsiflexion of right big toe \\ Dorsiflexion of right \\ Shield chest \\ Agenesis of left hemidiaphragm \\ Exomphalos \\ I: Genito-urinary \\ Cryptorchidism \\ Skin and subcutaneous tiss:re \\ Loose folds of skin
Loos \\ Widely spaced nipples \\ Poor subcutaneous tissue \\ Horizontal palmar crease \\ Arches on all toes \\ Hypoplastic finger- and toe-nails
}

* Abnormalities that can be found in thalidomide embryopathy

The heart weighed $8.8 \mathrm{~g}$. and lay in the right hemithorax. There was a high posterior membranous interventricular septal defect. The pulmonary valve was bicuspid. The foramen ovale and ductus arteriosus were both closed. The lungs were abnormally lobulated: the right bilobed and the left with fissures rudimentarily developed. The left hemidiaphragm was totally deficient with no vestige of a diaphragm segment so that the right hemidiaphragm connected directly to the left mediastinal wall. The pleura was completely continuous with the peritoneum.

There was a large exomphalos which contained the stomach, loops of the small intestine, and a part of the right liver (Riedel's lobe). The right umbilical artery was absent. The large intestine was malrotated. The sigmoid and rectum were both dilated but there was no anal stenosis. The pelvis appeared small. The testicles lay near the pelvic brim.
The brain showed absence of the falx cerebri, and the cerebellum was small. The kidneys, adrenals, pancreas, lymph nodes, and thymus were normal.

The abnormalities of the infant are summarized in the Table.

\section{Discussion}

The main abnormalities of the present case are an odd-shaped skull, low-set malformed ears, triangular mouth, receding chin, high-arched palate, webbing of the neck, shield-like chest, phocomelia of arms, ventricular septal defect with bicuspid pulmonic valve, agenesis of the left hemidiaphragm, abnormal lobulation of the lungs, cryptorchidism, Riedel's lobe of the liver, mesenterium commune, rockerbottom feet, short big toes, and partial syndactyly of toes.

Most of these abnormalities have been described by various authors in association with the 17-18 trisomy syndrome (Edwards et al., 1960; Smith et al., 1962; Uchida et al., 1962; Gottlieb et al., 1962) with the exception of the phocomelia, exomphalos, and agenesis of the left hemidiaphragm. However, one of us (Oikawa, Kochen, Schorr, and Hirschhorn, 1963) has observed two cases of 17-18 trisomy syndrome with phocomelia of arms (thalidomide ingestion was excluded in both cases:. In one of these there was agenesis of the left radius in addition to typical features of the 17-18 trisomy syndrome. The other infant also presented with aplasia of the left thumb, and agenesis of the left radius and ulna. Chromosome studies revealed in one infant the presence of complete chromosome trisomy with an extra chromosome 17 , and in the other a probable partial trisomy with translocation of a part of chromosome 17 to a chromosome of group 13-15.

Such malformations of the diaphragm and umbilicus as are commonly found in the 17-18 syndrome are partial defects of diaphragmatic musculature, with or without eventration of the diaphragm, and umbilical hernia. Agenesis of hemidiaphragm and exomphalos, as were seen in the present case, have not been described in association with the syndrome. A recent chromosome study of abortuses and stillborn infants (Carr, 1963) indicates that chromosomal abnormalities are a significant cause of early embryonic wastage. This makes us speculate that further studies in abortuses and stillbirths should reveal a foetus with 17-18 trisomy and severer malformations that lead to foetal death.

In the present case the mother's last menstrual period is known to have been January 17 to 20,1958 . The critical period for inducing thalidomide embryopathy is 34 to 60 days (Lenz and Knapp, 1962; Knapp, Lenz, and Nowack, 1962; Weicker, Bachmann, Pfeiffer, and Gleiss, 1962) after the first 
day of the last menstrual period. In this case it was February 20 to March 18, 1958. Since thalidomide was made available to the public on January 20, 1958 in this country, the possibility of the mother's taking thalidomide during the period cannot be totally ruled out. Phocomelia of arms with deformities of thumbs, congenital heart defects, malformation of the intestine, defect of the diaphragm, single umbilical artery (Kajii, Shinohara, Kikuchi, Dohmen, and Akichika, 1963), oligodactyly, and syndactyly have frequently been noted in thalidomide embryopathy. However, we know of no case of thalidomide-like embryopathy born in 1958 in Hokkaido, most such cases having been born during the year 1962. The phocomelia in thalidomide cases is always bilateral, though there is usually a slight asymmetry of the arms. In our case there is a greater difference than would be expected in thalidomide-induced phocomelia.

Since the foetus had been preserved for nearly five years a chromosomal study was naturally impossible. This case has, however, a series of malformations that fit those of the 17-18 trisomy syndrome, and make this diagnosis highly probable.

Potter (1961) describes a syndrome of renal agenesis, characterized by low-set malformed ears, a receding chin, and the appearance of an 'old man', but the illustration in the relevant chapter of her book shows the typical flexion and deviation of the fingers of a child with 17-18 trisomy syndrome. Potter's renal agenesis syndrome may thus be in reality a severe form of the 17-18 trisomy syndrome. The present infant, being born in 1958, gives further proof that the syndrome was present before the discovery of the chromosomal aberration (Edwards et al., 1960; Smith et al., 1960).

\section{Summary}

Clinical and necropsy findings of an infant who died in 1958 are described. There was phocomelia of the left arm, an absence of the left hemidiaphragm, and exomphalos, in addition to typical features of the 17-18 trisomy syndrome. This combination of malformations was interpreted as an expression of a severe form of the syndrome.

We should like to thank Dr. Matsuoka and Mr. T. Takahashi of Tonan Hospital, Sapporo, for preparing the photographs.

Carr. D. H. (1963). Chromosome studies in abortuses and stillborn infants. Lancet. 2. 603.

Edwards. J. H.. Harnden. D. G.. Cameron. A. H.. Crosse V. M., and Wolff. O. H. (1960). A new trisomic syndrome. ibid., 1, 787.

German. J. L.. III. Rankin. J. K.. Harrison. P. A.. Donovan. D. J., Hogan. W. J., and Bearn. A. G. (1962). Autosomal trisomy of a group 16-18 chromosome. J. Pediat., 60, 503.

Gottlieb. M. I. Hirschhorn, K. Cooper. H. L. Lusskin. N.. Mołoshok, R. E.. and Hodes. H. L. (1962). Trisomy-17 syndrome. Report of three cases and review of the literature. Amer. J. Med., 33. 763.

Hecht. F.. Bryant. J. S., Motulsky. A. G.. and Giblett, E. R. (1963). The No. 17-18 (E) trisomy syndrome. J. Pediat.. 63, 605.

Kajii. T.. and Shinohara. M. (1963). Thalidomide in Japan. Lancet, 1. 501.

Thalidomide and the umbilical artery. ibid. 2. 889

Knapp. K.. Lenz. W., and Nowack. E. (1962). Multiple congenital abnormalities. ibid.. 2.725.

Lenz. W.. and Knapp. K. (1962) Die Thalidomid-Embryopathie. Disch. med. Wschr.. 87, 1232.

Oikawa, K., Kochen. J. A.. Schorr. J. B., and Hirschhorn, K. (1963). Trisomy-17 syndrome with phocomelia due to complete and partial chromosomal trisomy. (Abstract, 33rd Meeting Soc. Pediat. Res.). J. Pediat. 63. 715.

Potter, E. L (1961) Pathology of the Fetus and Infant, 2nd ed., pp. 429-431. Year Book Medical Publishers. Chicago.

Smith. D. W.. Patau, K.. Therman. E.. and Inhorn. S. L. (1960). A new autosomal trisomy syndrome. J. Pediat. . 57, 338.

- _ - - - (1962). The No. 18 trisomy syndrome. ibid. 60.513.

Uchida, I. A., Bowman, J. M.. and Wang. H. C. (1962). The 18trisomy syndrome. New Engl. J. Med.. 266. 1198.

Weicker. H., Bachmann. K. D.. Pfeiffer, R. A., and Gleiss. J. (1962). Thalidomid-Embryopathie. Dtsch. med. Wschr., 87, 1597. 